East African Medical Journal Vol. 81 No. 5 May 2004

LAPAROSCOPIC ASSISTED VAGINAL HYSTERECTOMY FOR BENIGN UTERINE PATHOLOGY: IS IT TIME TO CHANGE?

R. B. Parkar, MBBS, MMed (Ob/Gyn), Consultant Obstetrician and Gynaecologist, P.O Box 520, Sarit Centre, 00606, Nairobi, N. G. Thagana, MBChB, MMed (Ob/Gyn), Consultant Obstetrician and Gynaecologist, P.O Box 75163, Nairobi and D. Otieno, MBChB, MMed (Anaes), Consultant Anaesthetist P.O. Box 19990 Nairobi, Kenya

Request for reprints to: Dr. R.B. Parkar, P.O. Box 520, Sarit Centre 00606, Nairobi, Kenya

\title{
LAPAROSCOPIC ASSISTED VAGINAL HYSTERECTOMY FOR BENIGN UTERINE PATHOLOGY: IS IT TIME TO CHANGE?
}

\author{
R. B. PARKAR, N. G. THAGANA and D. OTIENO
}

\begin{abstract}
Objective: To determine the acceptability and outcome of laparoscopic assisted vaginal hysterectomy at the Aga Khan Hospital, Nairobi.

Design: A retrospective case analysis.

Subjects: Two hundrend and twenty nine cases of laparoscopic assisted hysterectomy were undertaken at various hospitals in the presence of the principal author from May 2000 to December 2003. Of these $149(65.06 \%)$ were performed at the Aga Khan Hospital, Nairobi. These cases have been reviewed, analysed and presented.

Exclusions: All cases performed at the various other hospitals were excluded, along with those cases of laparoscopic assisted vaginal hysterectomy which are now being performed by other consultants obstetricians and gynaecologists, on their own and who have now learnt the technique

Results: Over the last three years, 149 cases of laparoscopic assisted vaginal hysterectomy were undertaken at the Aga Khan Hospital, Nairobi. Annual case load increased from three cases in 2000, to 71 cases by December, 2003. Fifty one percent of the patients were between 46 to 50 years of age, while $93.9 \%$ were para $2+0$ and above. Menorrhagia was the presenting complaint in $55.7 \%$. The operative procedure was performed in 91 to 120 minutes in $58.3 \%$ of the cases. Hospital stays were two nights in $95.3 \%$. The complications encountered were bladder injury $(3.4 \%)$, bowel injury $(1.3 \%)$, port site herniation $(0.67 \%)$ and a delayed recognition of bladder injury $(0.67 \%)$.

Conclusion: In Kenya, laparoscopic surgery is gradually being accepted by gynaecologists and general surgeons. The conversion from total abdominal hysterectomy to laparoscopic assisted vaginal hysterectomy for benign uterine pathology is now becoming more popular amongst gynaecologists and patients. With time laparoscopic assistance during hysterectomy will become the norm.
\end{abstract}

\section{INTRODUCTION}

Hysterectomy has traditionally been performed by the abdominal route (TAH). In the presence of significant uterine prolapse, the vaginal route $(\mathrm{VH})$ has been the preferred option(1).

As recently as 15 years ago, in the United States of America upto two thirds of all hysterectomies were still being performed by laparotomy(2). In large scale studies by Dicker et al.(1) and Wilcox et al.(2) only $30 \%$ of hysterectomies were performed vaginally.

Over the last 10 years, with the advent of advanced optics, technology developments, instrumentation and increasing confidence and surgical experience in laparoscopy, several newer options are being considered, constantly, re-evaluated and increasingly being accepted as the norm(3). There has been a marked increase in the use of laparoscopic access and assistance to carry out abdominal surgery, including hysterectomy(3). Since, Harry Reich in 1989 reported the first laparoscopic assisted vaginal hysterectomy, many centres worldwide have described their experiences with the use of laparoscopic access in performing hysterectomy, varying from the laparoscopic assisted vaginal hysterectomy (LAVH) to the total laparoscopic hysterectomy, (TLH), and the laparoscopic subtotal hysterectomy (LSH),(4). Fernandez et al. in 2000 reported a major decline in the rate of abdominal hysterectomy in favour of the laparoscopic assisted vaginal hysterectomy(5).

Laparoscopic assisted vaginal hysterectomy is associated with less morbidity and many centres are now reporting an increase in such procedures, replacing total abdominal hysterectomy $(4,5)$.

There are distinct advantages for the patient when a hysterectomy is done either vaginally or with laparoscopic assistance, rather than abdominally. The vaginal component is almost entirely extraperitoneal with minimal manipulation of the bowel, hence less post operative ileus. Patients are able to ambulate earlier, recover faster,with less incidence of thromboembolism, and therefore can be discharged from hospitals sooner, with obvious cost savings(5). 
Raju and Auld in their randomised prospective study demonstrated a shorter hospital stay (3.5 vs 6 days) and shorter convalescence (3 vs 6 weeks) for those undergoing laparoscopic assisted vaginal hysterectomy compared to the abdominal approach(6).

In Kenya, since May 2000, there has been a shift of options and several consultants (Obstetricians and Gynaecologists) in private practice, are opting for LAVH in selected cases, instead of the total abdominal hysterectomy. The full potential and acceptability of changing the norm has yet to be realised. In this paper an initial experience with laparoscopic assisted vaginal hysterectomy over a three year period is presented.

\section{MATERIALS AND METHODS}

A retrospective case analysis of all laparoscopic assisted vaginal hysterectomy's done at the Aga Khan Hospital, Nairobi, between May 2000 and December 2003 was conducted.

All cases whose records were incomplete or not obtained, and those lost to follow up were not included in the study. Cases undertaken at the Nairobi Hospital, Avenue Hospital, Aga Khan Hospital, Mombasa, the Nairobi Womens Hospital, M P Shah Hospital, Coast Province General Hospital, and the Kenyatta National Hospital were excluded, since they were occassional and follow up was a constraint.

At the Aga Khan Hospital, Nairobi a standard Karl Storz tower consisting of two Sony 21 inch monitors, a Trican SL Pal Camera, a Xenon 300 light source, and electronic endoflator, an Autocon 350 high frequency diathermy unit and a Unimat aquapurator were used for all the cases.

In theatre, under general anaesthesia, patients were cleaned and draped. Aseptic catheterization was undertaken routinely, and an examination under anaesthesia performed to determine, uterine size, position, mobility and the presence or absence of any adnexial pathology.

The procedure of laparoscopic entry for all the cases was standard. Initial pneumoperitoneum was created via a verres needle through an intra umbilical vertical stab incision. The initial $\mathrm{CO}^{2}$ insufflation pressure was maintained at $25 \mathrm{mmHg}$ and the flow rate of 1 litre per minute. Once an adequate and tense abdominal distention was obtained, a 10 $\mathrm{mm}$ trocar was inserted through the umbilical port. A $0^{\circ}$ or $30^{\circ} 10 \mathrm{~mm}$ laparoscope was then inserted, and subsequently the intra abdominal pressure was reduced and maintained at $15 \mathrm{~mm} \mathrm{Hg}$ and the flow rate increased to 20 litres/minute.

All secondary trocars $(5 \mathrm{~mm})$ were introduced strictly under direct vision. Initially the upper abdomen, the mid abdomen and the pelvis were inspected, and any underlying pathology, noted. Any adhesions, were released by sharp dissection. The operative technique for LAVH started by cauterization, with bipolar coagulation and sharp dissected of the round ligament, fallopian tubes, ovarian ligaments and the broad ligaments bilaterally upto the level of the uterine arteries. In some cases a harmonic scalpel was used for the same.

The uterovesical fold of peritoneum was then identified, dissected and the bladder was adequately reflected caudally. All attempts were made to reflect the posterior peritoneum off the cervix by sharp dissection after the uterosaccral ligaments were transected. Upon completion if the uterine arteries were well skeletonised, they were sutured laparoscopically, using intracorporrhoeal sutures, if not, at this stage, the laparoscope was removed and the abdomen was deflated. After adequate vaginal retraction the anterior and posterior vault were opened. Subsequently, the cardinal ligaments identified, clamped, and ligated.

If the uterine arteries were not tackled laparoscopically, they were then identified, clamped and ligated at this stage. The uterus thus being freed, was delivered vaginally. Uterine extraction was assisted by (vaginal) myomectomy of upto 8 Fibroids in four cases. The vault was then closed vaginally after ensuring adequate haemostasis. The abdomen was subsequently reinflated and a second look laparoscopic inspection undertaken. A generous lavage, was undertaken to confirm adequate haemostasis. In some cases peritonization of the vault was undertaken laparoscopically using intracorporhoeal sutures. However, this was not routine. The ureters were visualised bilaterally for adequate peristalsis. The $\mathrm{CO}^{2}$ gas was once again released, and the secondary ports removed under vision. The $10 \mathrm{~mm}$ umbilical port and laparoscope were also removed under direct vision. The bladder was catheterized to ensure clear urine, and a rectal examination was performed routinely. All ports of $10 \mathrm{~mm}$ and larger had the rectus sheath closed separately by interrupted sutures.

The records and clinical data for the procedures, including operative times, complications and follow up were adequately maintained on a Toshiba Satellite 4070 CDS laptop computer.

\section{RESULTS}

In the above period between May 2000 and December, 2003, 20.6\% of all laparoscopic surgery cases undertaken were LAVH (Table 1). Of the 229 cases of LAVH performed at all the hospitals, 149 of the LAVH performed at the Aga Khan Hospital, Nairobi $(65.0 \%)$ were reviewed for the purposes of the study.

The case load increased from three cases in 2000, when the principal author relocated his practice from Mombasa ( May 2000 ), to 71 in 2003. By January 2003, several other Consultant Obstetrician and Gynaecologists who had developed significant skills, were performing cases on their own, and these cases have not been included in the case review, since adequate data was not availed, for the purpose of this paper. 
Table 1

Total cases of laparoscopic assisted vaginal hysterectomy

\begin{tabular}{|c|c|c|c|c|c|c|c|c|c|c|c|}
\hline \multirow[b]{2}{*}{ Year } & \multirow{2}{*}{\multicolumn{2}{|c|}{$\begin{array}{l}\text { Total cases } \\
\text { of laparoscopic } \\
\text { surgery underta }\end{array}$}} & \multirow[t]{2}{*}{$\begin{array}{l}\text { AKH,N } \\
\text { ken }\end{array}$} & \multirow[t]{2}{*}{$\mathrm{NWH}$} & \multirow[t]{2}{*}{$\begin{array}{l}\text { Lap } \\
\mathrm{NH}\end{array}$} & \multirow[t]{2}{*}{$\begin{array}{l}\text { opic } \\
\text { AH }\end{array}$} & \multirow[t]{2}{*}{$\begin{array}{l}\text { isted vagir } \\
\text { AKH,M }\end{array}$} & \multirow[t]{2}{*}{$\begin{array}{l}1 \text { hystere } \\
\text { CPGH }\end{array}$} & \multirow[t]{2}{*}{ KNH } & \multirow[t]{2}{*}{$\begin{array}{l}\text { VH) done } \\
\text { MPSH }\end{array}$} & \multirow[t]{2}{*}{$\begin{array}{c}\text { Total LAVH } \\
\text { Done }\end{array}$} \\
\hline & & & & & & & & & & & \\
\hline $\begin{array}{l}2000 \\
\text { (May to }\end{array}$ & Dec) & 56 & 3 & - & - & - & - & - & - & - & 3 \\
\hline 2001 & & 309 & 28 & 1 & 3 & - & - & - & - & - & 32 \\
\hline 2002 & & 349 & 47 & - & 25 & 2 & 1 & - & - & - & 54 \\
\hline 2003 & & 397 & 71 & 1 & 37 & - & 3 & 1 & 2 & 4 & 78 \\
\hline Total & & 111 & 149 & 2 & 65 & 2 & 4 & 1 & 2 & 4 & 229 \\
\hline
\end{tabular}

Key: AKH, N= Aga Khan Hospital, Nairobi, AKH, M= Aga Khan Hospital, Mombasa, NH= Nairobi Hospital, KHN: Kenyatta National Hospital, AH= Avenue Hospital, CPGH= Coast Province General Hospital, NWH= Nairobi Womens Hospital, MPSH= MP Shah Hospital,

\section{Table 2}

Age and parity of laparoscopic assisted vaginal hysterectomy patients ( $n=149)$

\begin{tabular}{llllllll}
\hline Age (years) & 0 & 1 & 2 & 3 & 4 & 5 and more & Total \\
\hline $35-40$ & - & 1 & 14 & 1 & - & - & 16 \\
$41-45$ & - & 3 & 10 & 26 & 7 & 2 & 48 \\
$46-50$ & 2 & 1 & 7 & 63 & 2 & 1 & 76 \\
$51-55$ & - & 1 & 4 & 1 & - & - & 6 \\
Above 56 & - & 1 & 2 & - & - & 3 & 149 \\
\hline
\end{tabular}

Of all the cases undertaken, $51.0 \%$ of the patients were in the 46 to 50 year age bracket, while $93.9 \%$ were para 2 and above (Table 2). It is worthwhile to note that 137 cases $91.9 \%$ were para 3 and below. In these patients generally, vaginal descent of the uterus,

Table 3

Presenting complaints $(n=149)$

\begin{tabular}{ll}
\hline Complaint & No. \\
\hline Menorrhagia & $86(57.7 \%)$ \\
Dysmenorrhoea/Chronic pelvic pain & 27 \\
intermenstrual bleeding & 21 \\
Post coital bleeding (normal pap smears) & 9 \\
Asymptomatic uterine fibroids & 3 \\
Renal changes on IVP & 3 \\
\hline
\end{tabular}

facilitating a vaginal hysterectomy only, is limited. It is therefore the laparoscopic component of the procedure, that creates the descent so required in order to complete a laparoscopic assisted vaginal hysterectomy.

\section{Table 4}

Significant previous surgery $(n=149)$

\begin{tabular}{lc}
\hline Surgery & No. \\
\hline Caesarean Section & $33(22.1 \%)$ \\
Laparoscopy & 19 \\
Myomectomy & 14 \\
Laparotomy ( Gynaecological indications) & 12 \\
Appendicectomy & 12 \\
No previous surgery & 65 \\
\hline
\end{tabular}


Table 5

Operating Times $(n=149)$

\begin{tabular}{ll}
\hline Operating time (minutes) & \\
\hline Less than 60 & 2 \\
$61-90$ & 21 \\
$91-120$ & $87(58.3 \%)$ \\
$180-120$ & 25 \\
More than 120 & 9 \\
Time not recorded & 5 \\
\hline
\end{tabular}

The operating times for the laparoscopic assisted vaginal hysterectomy varied from 45 minutes to 245 minutes, with $58.3 \%$ of the procedures being done between 91 and 120 minutes (Table 5). During the learning curve phase of the procedures undertaken, the procedures were generally longer, but as surgeons acquired the necessary skills, and as the " team " work became established and apparent the procedures were relatively shorter, and the time taken for the procedures, became shorter.

Table 6

Uterine weight (grams)

Uterine weights (grams)

\begin{tabular}{ll}
\hline$>100$ & 2 \\
$101-250$ & 19 \\
$251-500$ & $85(57.0 \%)$ \\
$501-750$ & 24 \\
$751-1000$ & 13 \\
$\leq 1000$ & 6 \\
\hline
\end{tabular}

Uterine size, was recorded by the pathological weights of the specimens (Table 6). The smallest uterus weighed 82 grams and the largest being 1269 grams. Fifty seven percent of the uteri weighed between 251 and 500 grams. Vaginal delivery of large uteri was assisted by vaginal enucleation of uterine fibroids, bisection and in one case a laparoscopic myomectomy.

Hospital stays varied from two nights in 142 of the 149 patients $(95.3 \%)$ to four nights in six patients, while one patient with a delayed recognition of a bladder injury spent 29 days in hospital. There were no cases converted to a TAH intraoperatively, as result of a difficult procedure. Laparotomy was undertaken in five patients intra operatively due to a recognised complication (bladder injury or rectal injury), (3.4\%), and two additional patients underwent laparotomy after day seven $(1.3 \%)$ as a result of a delayed complication, one with intestinal obstruction resulting from post site herniation of the small bowel and one from a delayed diagnosis of a bladder injury. One patient had the LAVH postponed due to ventricular fibrillation on induction of anaesthesia, two patients had " small " bladder tears which were repaired laparoscopically by intracorporrhoeal (laparoscopic) suturing, one patient had a laparotomy on day three, for an intra abdominal bleed, and two patients had exploration of the umbilical port site after day seven, for omental evisceration.

\section{Table 7}

Complications of laparoscopic assisted vaginal hysterectomy

\begin{tabular}{ll}
\hline Intraoperative & \\
Bladder injury (repaired by laparotomy) & 3 \\
Bladder injury (repaired laparoscopically) & $2(3.4 \%)$ \\
$\begin{array}{l}\text { Ventricular Fibrillation (on induction } \\
\text { of anaesthesia) }\end{array}$ & 1 \\
Bowel Injury & $2(1.3 \%)$ \\
Post & \\
$\quad \begin{array}{l}\text { Within } 24 \text { hours } \\
\text { Within } 3 \text { days: (intra abdominal }\end{array}$ & 0 \\
haemorrhage) & $1(0.67 \%)$ \\
$\begin{array}{l}\text { With } 7 \text { days: Omental evisceration } \\
\text { Post site herniation } \\
\text { (intestinal obstruction) }\end{array}$ & 2 \\
$\begin{array}{l}\text { Within } 42 \text { days } \\
\text { Bladder Injury } \\
\text { (delayed recognition) }\end{array}$ & $1(0.67 \%)$ \\
\hline
\end{tabular}

Table 8

Laparotomy conversion

\begin{tabular}{ll} 
Intra - operative & \\
To total abdominal & \\
hysterectomy & \\
For recognised complication & $5(3.4 \%)$ \\
& \\
Post - operative & \\
Within 3 days & $1(0 . .67 \%)$ \\
after day 7 & $2(1.3 \%)$ \\
\hline
\end{tabular}

Table 9

Histology $(n=149)$

\begin{tabular}{ll}
\hline Uterine fibroids & $96(64.4 \%)$ \\
Adenomyosis & 21 \\
Endometrial hyperplasia & 12 \\
Endometrial polyps & 9 \\
CIN & 6 \\
Endometrial carcinoma & 2 \\
Abnormal uterine bleeding & 3 \\
\hline
\end{tabular}

\section{DISCUSSION}

Hysterectomy is the second most frequently performed major surgical procedure, after Caesarian section amongst women of reproductive age(7). It is one of the commonest elective surgical procedures and by 50 years of age $20 \%$ of U.K. women have undergone a hysterectomy(8), and one in three women in the United States by 60 years of age(9). Majority of these hysterectomies are performed abdominally. The first report of laparoscopically assisted vaginal hysterectomy 
appeared in 1989(13). Reich et al. recommended the laparoscopic assisted vaginal hysterectomy in patients presenting with possible adhesions from previous surgery, endometriosis, an excessively large uterus or patients with potential tumours or cysts. These cases are considered as poor candidates for the traditional vaginal hysterectomy(10).

Although vaginal hysterectomy can produce excellent results in experienced hands, it does not allow the facility to precisely define and deal with any potential intraabdominal pathology(10).

In Kenya, Parkar et al. reported the first cases of LAVH(11). The outcomes of 149 cases of locally performed LAVH were analysed, in this paper.

Trehan in 2002, noted that patients could be possibly discharged considerably earlier than was the norm for hysterectomies and reported a total of 117 cases of overnight stays in a series of 265 hysterectomies performed(12). In his series $4.5 \%$ suffered some complications which included a Richters hernia, secondary bleeding, subrectus haematoma and one conversion to TAH for a large fibroid. In our series, $95.3 \%$ of our patients spent two nights in hospital, and complications encountered in $8.7 \%$ of the cases undertaken. These included bladder injury, bowel injury, one case of ventricular fibrillation on induction of anaesthesia, one case of delayed intra abdominal bleed, omental evisceration through the umbilical port, and in one case intestinal obstruction following a port site herniation. Garry noted that although laparoscopic surgery had a tremendous potential, a known intraoperative complication rate of between $1 \%$ to $10 \%$ has been documented in various Journals(13). Brosens et al. reported that bowel injuries during laparoscopic surgery range from 1 in 1652 procedures to 1 in 280 procedures, and are dependant on the level of surgical expertise. It was also noted that adhesions from previous surgery, pelvic infections and endometriosis predispose to injuries(14). Miranda et al. in 2000 reported one major vessel injury, two intestinal injuries $(0.2 \%)$, one anaesthetic complication and two urinary tract injuries $(0.2 \%)$ in a series of 1649 operative laparoscopies(15).

Our case load was obtained from a pool of consultants, who have been receiving regular training in laparoscopic surgery. Although our initial operating times were higher, as more and more procedures were performed, and surgeons acquired sufficient skills, the operating times shortened and complications encountered became fewer.

Trehan in his series reported his mean operating time to range from 55 to 205 minutes(12). Richardson et al.(16) and Summit et al.(17) reported operating times for LAVH to be 125 minutes compared to 51 minutes for vaginal hysterectomies. Similarly the mean operating times for TAH was 75 minutes compared to 126 minutes for the LAVH group $(16,17)$. In our series, operating times were between 45 to 245 minutes.
In $58.3 \%$ the operating times were between 91 to 120 minutes. The factors that contribute largely to longer operating times include the inclusion of adjunctive procedures, gross pathology, and the laparoscopic re-evaluation after vault closure(17). This includes an extra few minutes for adhesiolysis, excision of peritoneal endometriosis, or ovarian cysts and vault bleeding.

Najia et al.(18) reviewed 99 hysterectomies, 92 of which were done by the vaginal route. There was no significant prolapse in $78 \%$ of the patients. It was recommended that a preliminary laparoscopy should be encouraged in all patients so as to enable adequate selection and to remedy any existing intraabdominal pathology. In our review no significant prolapse was evident in any of our patients, and laparoscopy was performed routinely pre and post vaginal intervention. In two cases laparoscopic myomectomy with morcellation was undertaken to reduce the uterine size prior to commencing the LAVH procedure. Kovak et al. recommended that the role of a preliminary laparoscopy for any suspected contra indication to the vaginal hysterectomy should never be understated(19).

Johns et al.(20) showed a major complication rate of $1.7 \%$ for LAVH, $2.5 \%$ for abdominal hysterectomy and $1.0 \%$ for the vaginal hysterectomy(21). Brechin et al. undertook an evaluation of 505 LAVH in Scotland. Although the uptake of laparoscopic assisted vaginal hysterectomy overall in Scotland was relatively low, with only a few Surgeons performing majority of the procedures, patients satisfaction with the procedure was extremely high and the complication rates of $18.2 \%$ primarily on account of post operative infections were noted(21). Una Fahy et al.(22) reported in a comparism of convalescence in women following LAVH and following $\mathrm{TAH}$ in 72 patients that the physical functioning scores (5F36) were similar both pre operatively and at one week after the operation, in women who had an LAVH $(n=35)$ and in those who had the conventional TAH $(n=37)$. However six weeks after the operation, women who underwent a LAVH had significantly higher physical functioning scores (26, range $19-30$ vs 22, range $14-30 ; p=0.041$ ) and significantly less reduction in physical functioning scores relative to the baseline than in the conventional hysterectomy group (3\% vs 13\%; p = 0.031)(22).

In our series patients were routinely discharged when they no longer required intramuscular or intravenous analgesia were ambulatory, were tolerating their diets adequately and were voiding spontaneously. Mehra et al.(23) documented the comparison of vaginal (vaginal hysterectomy) TAH and LAVH in 663 patients undergoing hysterectomies for various indications over a three year period. The estimated blood loss was significantly low in the LAVH and vaginal hysterectomy group. The operating time was longer in the LAVH groups than for the TAH groups which in time was longer when compared to the vaginal hysterectomy 
group. Complications were $31.3 \%, 13.7 \%$ and $12.3 \%$ in the TAH, LAVH, and vaginal hysterectomy groups respectively. The length of stay in the hospital was found to be least for LAVH and greatest from TAH $(\mathrm{P}=0.001)$. The total costs for all three types of hysterectomy were not significantly different $(\mathrm{P}>0.05)$. Women in the laparoscopic assisted vaginal hysterectomy and vaginal hysterectomy groups recovered sooner (16.4 \pm 3.4 and $18 \pm 4.2$ days respectively) than those in the TAH group $(30.8 \pm 7.2$ days $)(\mathrm{P}=0.001)(23)$.

\section{CONCLUSION}

In Kenya, the full potential of laparoscopic surgery has yet to be realised, and the conversion from TAH to hysterectomy with laparoscopic assistance is still not adequately accepted. Obura(24) classified Gynaecologists performing minimal access surgery into level $\mathrm{O}$ (those who do not practice minimal access surgery) level I (performing diagnostic procedures, minimal adhesiolysis, BTL, aspiration of simple ovarian cysts, and ovarian biopsies; Level II, (performing minimal access surgery for ectopic pregnancy, moderate adhesiolysis, tuboplasty, ovarian drilling, salpingo - oopherectomy, moderate endometriosis surgery) and level III (performing minimal access surgery for myomectomy, LAVH, TLH, extensive endometriosis, and pelvic Iymph node clearance). Obura(24) concluded that although the majority of respondents had a positive attitude towards minimal access surgery, only $6.3 \%$ were performing level III procedures.

\section{REFERENCES}

1. Dicker, R.C., Greenspan, J.R., and Strauss, L.T., Complications of abdominal and vaginal hysterectomy among women of reproductive age in the United States. Amer. J. Obstet. and Gynae. 1982; 144:841-847.

2. Wilcox, L., Koonin, L., Pokras, R., Strauss, L., Xia, Z., and Peterson, H. Hysterectomy in the United States, 1988 - 1990, Obstet. and Gynae. 1994; 83:549-555.

3. Simser, T. Karakus, C., Karaveli, S., and Trak, B., Laparoscopic assisted vaginal hysterectomy for benign uterine pathologies; could this be the first line of treatment? Gynae. Endoscopy. 2001; 10:361-364.

4. Boike, G., Elfstrand, E., Delpriore, G., et al. Laparoscopically assisted vaginal hysterectomy in a university hospital: report of 82 cases and comparison with abdominal and vaginal hysterectomy Amer. J. Obstet. and Gynae. 1993; 168:1690-1701.

5. Fernandez, H., Anquetil, C., Capella,-Allouc, S., Frydman, R., and Gomel, V., Hysterectomy for benign uterine disease: the effect of the introduction of laparoscopic assisted hysterectomy on the selection of surgical access. Gynae. Endoscopy. 2000; 9:167-174.
6. Raju, K.S., and Auld, B.J. A randomised prospective study of laparoscopic hysterectomy versus abdominal hysterectomy each with bilateral salpingo - oopherectomy. Brit. J. Obstet. and Gynae. 1994; 101:1068-1071.

7. Pokras, R., and Hufnegal V.G., Hysterectomies in the United States, 1964 - 1984 Amer. J. Public Hlth. 1998; 78:852-853.

8. Vessey, M.P. Villaid,-Mackintosh, L., Mcpheson, K., Coulter, A., and Veates, D., The epidemiology of Hysterectomy: findings in a large cohort study. Brit. $J$. Obstet. and Gynae. 1992; 99:402-407.

9. Parker, W.H., Total laparoscopic hysterectomy. Obstet. and Gynae. Clinics of North America. 2000; 27:431-440.

10. Reich. H., Decaprio J., and Mcglynn, F., Laparoscopic hysterectomy. J. Gynae. Surg. 1989; 5:213-218.

11. Parkar, R.B., Thagana, N.G, Baraza, R., and Otieno, D., Experience with laparoscopic surgery at the Aga Khan Hospital, Nairobi. East Afr. Med. J. 2003; 80:44-50.

12. Trehan, A.K., Hysterectomy: Towards overnight stay. Gynae. Endoscopy. 2002; 11:181-187.

13. Garry, R., Who is for endoscopic surgery and whom is endoscopic surgery for? (Editorial) Gynae. Endoscopy. 2000; 9:281-283.

14. Brosens, I., and Gordon, A., Bowel injuries during gynaecological laparoscopy. A multi national audit. Gynae. Endoscopy. 2001; 10:141-145.

15. Miranda, C.C., Carvajal, A.R., and Escobar, P., Complications of operative laparoscopy. Gynae. Endoscopy. 2000; 9:161-165.

16. Richardson, R.E., Bournas N., and Magos A.L., Is laparoscopic hysterectomy a waste of time? Lancet. 1995; 345:36-41

17. Summit, R.L., Stovall, T.G., Lipscomb, G.H., and Ling, F.W., Randomised comparison of laparoscopic assisted vaginal hysterectomy with standard vaginal hysterectomy in an outpatient setting. Obstet. and Gynae. 1992; 80:895-901.

18. Naja, S.K., Bhatia, K., and Hall, V., The route for hysterectomy: Is it time to change? Gynae. Endoscopy. 2002; 11:71-74.

19. Kovac, S.R., Cruikshank, S.H., and Retto, H.F., Laparoscopic assisted vaginal hysterectomy. J. Gynae. Surg. 1990; 6:185-193.

20. Johns, D.A., Carrera, B., Jones J., and Deleon, F., Economic impact of laparoscopically assisted vaginal hysterectomy in a large metropolitan not for profit hospital. Amer. J. Obstet. and Gynae. 1995; 172:1709-1719.

21. Brechin, S., Farqoharson, D.M., Haworth, R., et al. A Scottish audit of laparoscopically assisted vaginal hysterectomy. Gynae. Endoscop. 2000; 9:233-238.

22. Fahy, U., Watkins, K., Duffin, S., and Kirwan, P.H., Convalescence after laparoscopically assisted vaginal hysterectomy. Gynae Endoscopy. 2000; 9:55-58.

23. Mehra, S., Bhut, V., and Mehra, G., Laparoscopic vs. abdominal vs. vaginal hysterectomy Gynae. Endoscopy. 1999; 8:29-34.

24. Obura T., Knowledge, attitude and practice of minimal access surgery (M.A.S.) amongst Gynaecologists in Nairobi, Kenya, (unpublished) MMed Dissertation, University of Nairobi. 2002 